\title{
Constructive Methodologies to Overcome the Technological Barriers in Online Teaching-Learning Process
}

\author{
Sathyendra Bhat ${ }^{1}$, Ragesh Raju ${ }^{2}$, Shreeranga Bhat ${ }^{3}$, Rio D'Souza ${ }^{4}$, Athokpam Bikramjit Singh ${ }^{5}$ \\ ${ }^{1}$ Department of Computer Applications, St Joseph Engineering College, Mangaluru, Karnataka, India \\ ${ }^{2}$ Department of Computer Applications, St Joseph Engineering College, Mangaluru, Karnataka, India \\ ${ }^{3}$ Department of Mechanical Engineering, St Joseph Engineering College, Mangaluru, Karnataka, India \\ ${ }^{4}$ Department of Computer Science and Engineering, St Joseph Engineering College, Mangaluru, Karnataka, India \\ ${ }^{1}$ sathyendrab@sjec.ac.in \\ ${ }^{2}$ rageshr@sjec.ac.in \\ ${ }^{3}$ shreerangab@sjec.ac.in \\ ${ }^{4}$ riod@sjec.ac.in \\ ${ }^{5}$ bikramjits@sjec.ac.in
}

\begin{abstract}
:
Over the past few years, technology-driven learning has gained a lot of momentum in every spectrum of education, more so in the field of engineering education. Most of the engineering educators often get inclined towards technology to deliver their courses effectively. While teachers have started leveraging Learning Management Systems (LMS) effectively, some of the technological innovations still need a little refinement. This study intends to explore the limitations of Canvas which is one of the popular LMSs being used today. Although Canvas is an excellent tool to manage the course content effectively and has proved to be very user friendly, it still has some nagging issues which have been analyzed through this study. The ways to overcome these limitations have also been put forth to ensure that the potential adopters of Canvas may have a seamless experience. The participants of the study were 56 second year Post Graduate students who were undergoing the course titled Professional Communication and Report Writing. A handful of students ran into unknown issues while taking up the MultipleChoice Questions (MCQ) based quiz designed in the second module of the course. The issue was then traced, and corrective measures were incorporated to ensure that all students can take up the quiz. The analysis proved that MCQ quizzes developed on Canvas were not compatible with older versions of Android. Hence, students using such phones were unable to take up quiz-based assessments. To overcome this issue, the quizzes were dished out using tools like Google Forms, Kahoot, Quizizz, etc., and the links were posted on Canvas for the students to take up the quiz. While this approach worked relatively well, it was observed that each of these tools had their own set of limitations. In a nutshell, there is no technology that is perfect in all situations. In such circumstances, it is imperative that the course instructor takes centre stage and selects the technology that best suits a situation.
\end{abstract}

Keywords: Engineering Education, Learning Management System, Assessment, Technology, Online TeachingLearning

\section{Introduction}

In recent times, technology has been a gamechanger in the field of education. Although technology-based tools were being leveraged pre-pandemic times, the prevailing pandemic situation and resultant restrictions on offline teaching have opened up many avenues for teachers to switch entirely to online teaching. While online teaching is challenging for even an expert, the beginners have had to go through many struggles to get used to the online mode of teaching-learning. The reasons for this are quite obvious. Teachers all over the world have been asked to just jump into online teaching without adequate experience or training.

Technology plays a significant role in online teaching. The dependency on electronic gadgets and the internet has risen quite considerably over the past few months. However, harnessing the power of technology in education means much more than just the usage of gadgets and the internet.

While live lecturing is one facet of online teaching, this method has its own set of limitations. Live lectures demand the students be online and attend the lectures irrespective of their whereabouts. Most of the times, students tend to be at places with limited or no connectivity which makes it that much more difficult for the student to attend the live lecture. Even if there are no connectivity issues, the fickle reception of mobile internet compounds the problem even further. Moreover, students, as well as teachers who are dependent on their mobile internet connection, often run into issues with the amount of data available on their devices.

Recorded lectures are a counterpart of live lectures where a teacher is expected to record the lectures offline and make the recording available to the students who can then watch the recorded lecture at their own pace and space. While this approach seems quite reasonable, it requires a mechanism by which the teacher could share the video resources with the students. Although sharing the same via email or a messenger application like WhatsApp is an option, these are still not the most optimum methods. It is such situations where a Learning Management System (LMS) comes in handy (Rhode et al., 2017) and has proven to be the best fit 
for teachers to share course-related resources with their students conveniently.

Presently, most of the higher education institutions have adopted the usage of LMSs, while some of the institutions are on the verge of its adoption (Walker et al., 2016). This is mainly because academic institutions have been compelled to take their teaching-learning process entirely online (Toquero, 2020). Even though this unforeseen shift has been a difficult one, the advancements in technology has helped the academicians all over the globe a great deal and made their life tad bit easier. The LMS helps a teacher (Sinclair and Aho, 2018) organize the course content and share the same with the students promptly. When it comes to students, the LMS provides a galaxy of opportunities to learn the course at their convenience (Adnan and Anwar, 2020). Simply put, this promotes self-study (Priyatno, 2017), which has been the Achilles heel of the teachinglearning process over the decades.

As far as the LMSs are concerned, the teacher has a variety of options available. Some of the popular options include tools like Google Classroom, Canvas, Moodle, Blackboard, Edmodo, Lessonly, SAP Litmos, Oracle Cloud, to name a few. The beauty of this whole gamut of LMSs is that each one has its pros and cons. The LMS chosen for this study is Canvas (Baldwin and Ching, 2019) which one of the more preferred tools for a large number of teachers.

Canvas, as an LMS provides an open and easily extendable learning ecosystem for any academic institution. Canvas provides a mechanism for teachers to integrate the systems and apps they need to support every student, at every stage, in any learning environment.

\section{Literature Review}

As online teaching-learning process is quicky gaining momentum and is becoming the new normal, the academic institutions around the globe are confronted with a tough challenge of choosing an LMS that best meets the needs of the institution as well as all its stakeholders (Kasim and Khalid, 2016)

A lot of popular studies (Kats, 2010) show that live lectures in online teaching are inferior to their recorded counterparts due to a variety of factors. Straight live lectures delivered monotonously are not overly thought-provoking and fail to ignite interest among students. The students tend to learn better when the onus is on themselves to learn through selfstudy, which is one of the primary reasons for resorting to LMSs.

Another evolving area of the online teaching process is the emergence of cloud computing as a modern muse for leveraging LMSs (Aldheleai et al., 2017). This allows the teachers as well as the students to go beyond the technologies barries of hardware and software.

Although learning through the LMSs is unique and often result in pleasant experiences, the LMSs have their own set of disadvantages (Debuse and Lawley, 2016). To begin with, the teacher will be remotely monitoring the course content, which is devoid of the classical face-to-face communication, which is the backbone of any academic activity. However, LMSs have tried to overcome this barrier through chat and discussion forums, but these still leave a lot to be desired.

Instructure Canvas has proved to be an effective LMS that offers a whole lot of options to its users. Since the students in higher education, as well as technical education institutions, have diverse learning preferences, Canvas has become the go-to tool for many teachers. To add to it, Canvas also provides efficient interfaces to deal with students with disabilities (Lee, 2016) as well.

A recent study (Fathema and Akanda, 2020) carried out at the University of Wisconsin shows that Canvas as an LMS has had a lot of positive impact on the teachers as well as students. The study also recommends that prior LMS knowledge of the course instructor does have a bearing on its fruitfulness and can impact the usage of the system. However, the users of Canvas have managed to overcome all these limitations, which proves that it is easy and convenient to use for all its userbase.

Assessing the impact of online courses on student fraternity is an essential step in evaluating its effectiveness. Making a brief, easy-to-use checklist available that lists out precise guidelines (Baldwin and Ching, 2019) for the usage of any LMS is one of the vital parameters to be considered. In this regard, Canvas has proved its utility with a lot of related documentation that makes its usage explicit and straightforward.

Higher Education learners have become diverse with a variety of learning needs and preferences in addition to those with documented disabilities. Canada, unlike the US, does not have national legislation for providing support and access for learners with disabilities. This article identifies universal design for learning principles applications and recommendations to support learners of all abilities, including those with disabilities in the face to face and online classes using Instructure Canvas LMS.

\section{Methodology}

As most of the universities have moved towards online teaching, each of the academic institutions must be required to adopt a tool that best suits their requirement to support the online teaching-learning process. In this era of online education, a Learning Management System plays a central role by providing an effective gateway for teachers to disseminate the course content with their students. The authors of this paper have been extensively making use of Google Classroom (Bhat, 2018) as an LMS to deliver the courses over the past few years.

However, when the authors switched to Canvas LMS recently and started rolling out the course on Canvas, a few glaring assessment-related issues unearthed that have been made use of to analyze the usefulness of Canvas.

\section{A. Participants}

The participants for this study were 56 second year, fulltime students from the postgraduate department in computer applications and two teachers of the same department. Due to this nationwide lockdown caused due to the pandemic situation, the participants were forced to 
attend online classes sitting at remote locations with literally no face-to-face communication with the teacher.

\section{B. Study Design}

The participants of this study were undergoing the course "Professional Communication and Report Writing" that was conducted completely online. A course page was created on Canvas LMS, and all the students were added to the course. The teacher used to record lectures and post the same on Canvas at regular intervals. In addition to the recorded lectures, some additional learning resources like PPTs, OneNote PDFs, YouTube videos etc. were also shared through Canvas. The LMS was also used to open opportunities for students in the form of peer learning through discussion forums.

Coming to the assessments, since the course was being offered completely online, the assessments were also made available on Canvas LMS. The assessments included short quizzes, assignments and internal tests that all contributed to the formative assessment component.

\section{Problem Description}

While Canvas proved to be an exceptional tool to manage course content, some of the students faced a peculiar issue when they had to solve a Multiple-Choice Questions (MCQ) based quiz. Although most of the students in the class did not have any qualms about the quiz and managed to take it up without any hassles, there was a set of students who reported some strange problems while accessing the quiz assessment.

After having multiple deliberations on the same through the discussion forum on Canvas, it was found that all the students having trouble accessing the quiz were trying to do so on their smartphones. In pursuit of looking for other alternatives, it was observed that the students were able to access the quiz without any hassles on a computer but not on their mobile devices via the Canvas mobile app as well the mobile browser. This phenomenon was a testimony to the fact that the issue was something to do with accessing Canvas quizzes on mobile devices. Although the students were able to answer the quiz through the computer, the issue was traced, and corrective measures were incorporated to ensure that all students can take up the quiz through their smartphones also.

\section{Analysis}

As a part of the formative assessment, the students were asked to answer a Multiple-Choice Questions (MCQ) based quiz on Canvas. The quiz was prepared using built-in Quizzes option on Canvas (Westerveld and Deenen) tool itself, as shown in Fig 1. The quiz prepared this way, as shown in Fig 2, had accessibility issues when students tried to take it up, on their smartphones.

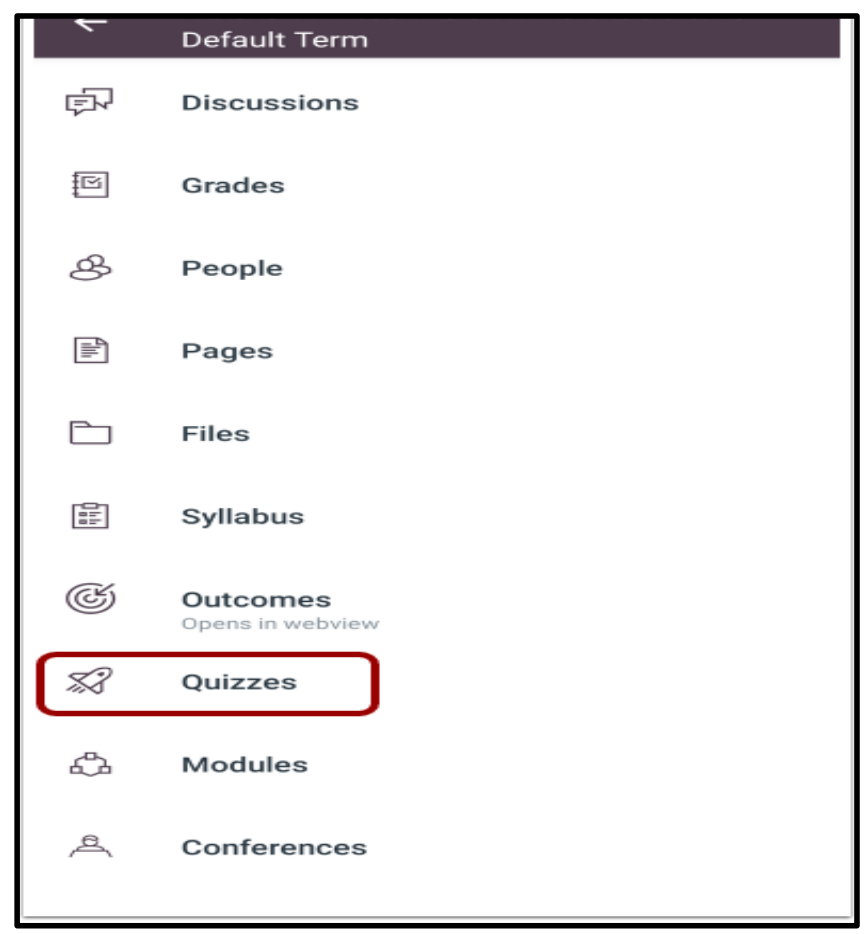

Fig. 1: Built-in quiz option on Canvas

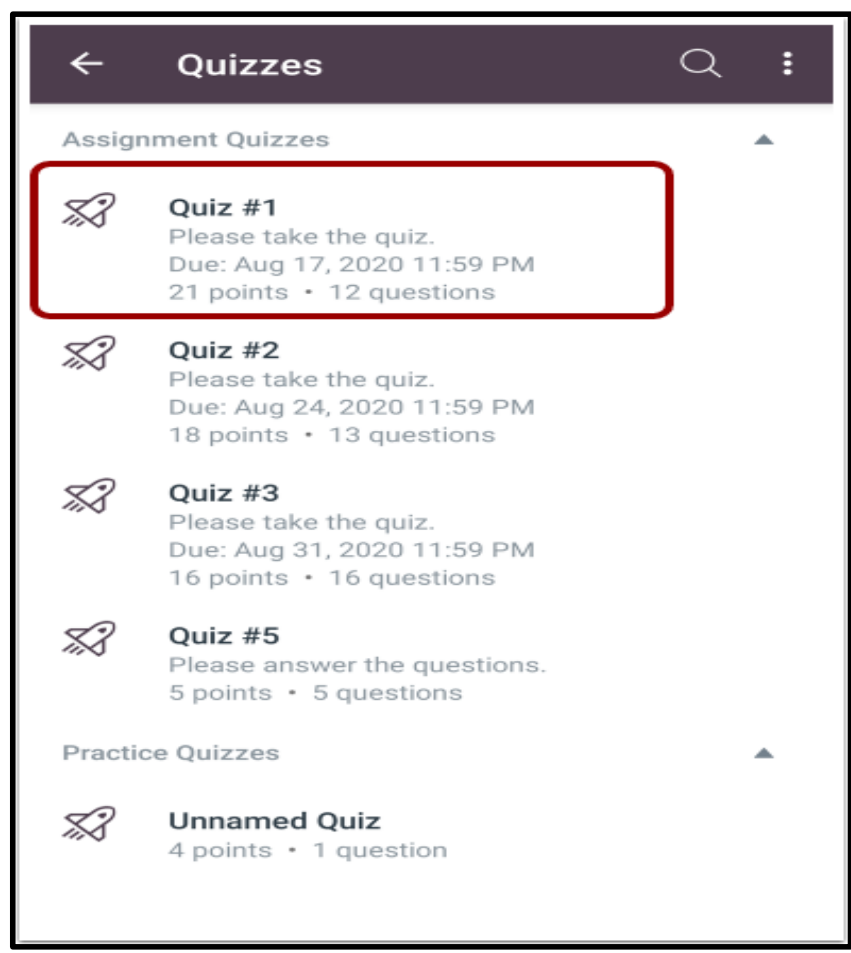

Fig. 2: The quiz that caused issues to some of the students in the class

While most of such students were trying to take up the quiz through the Canvas app, some of them were even trying to do so through the mobile web browser. However, both sets of students had the same issues wherein they were able to open the quiz shown in Fig 3 and go through the instructions, but they had trouble navigating between questions and viewing all the answer options. 


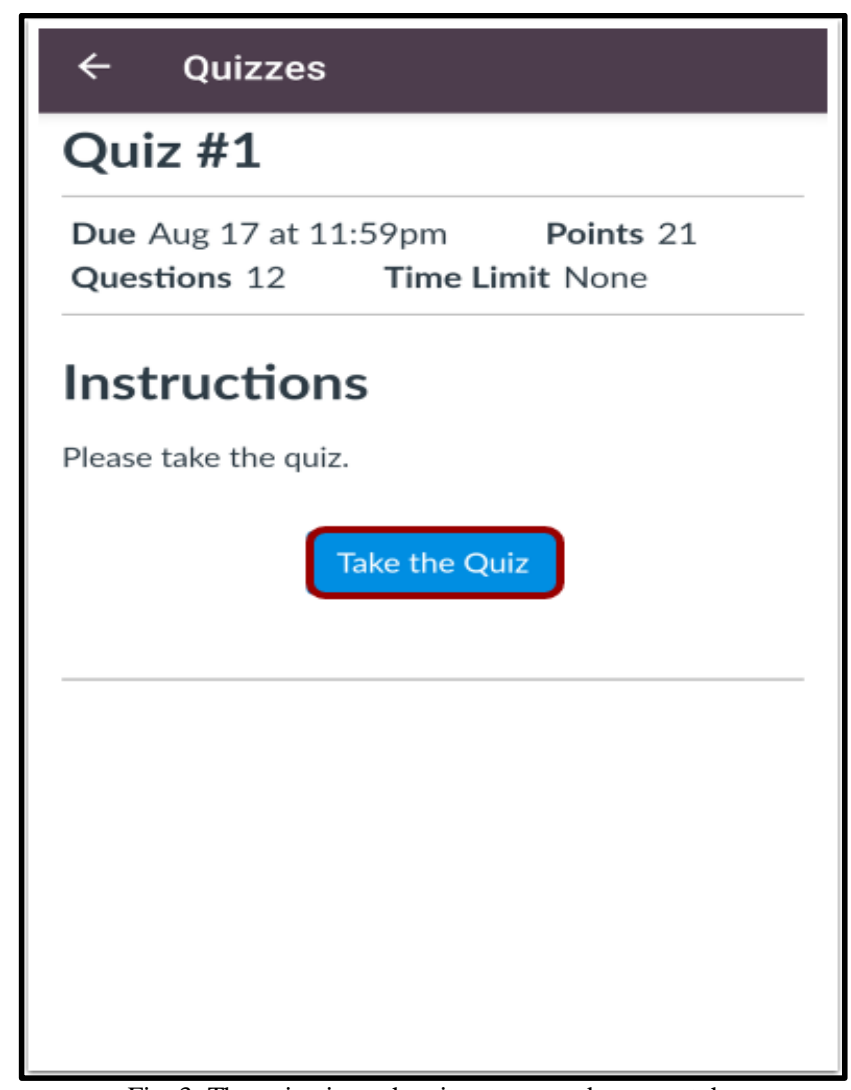

Fig. 3: The quiz view when it gets opened on smartphones

When this problem was traced, it was observed that these set of students who had issues accessing the quiz were trying to do so with Android smartphones running Android version 6-Marshmallow or below. However, to confirm this, the course instructor had to remove the clause of restricting the students to have only one attempt at the quiz. After removal of this clause, the same set of students tried to take up the test from Android devices running higher versions of Android, which allowed them to take up the quiz smoothly. However, to cross-check the issue, the course instructor dished out a couple more test quizzes of the same nature, and when the students tried again on their Android Marshmallow devices, they ran into the same issue. Again, as was the case with the previous quiz, the students were able to take up the same quiz on other devices running higher versions of Android, quite seamlessly. Hence, this experiment proved that Canvas does not provide much support on older versions of Android devices which results in these sort of nagging issues.

\section{Results and Discussion}

Even as the students were facing issues with the first quiz and before the problems with lower versions of Android was discovered, the course instructor tried to experiment with other tools in terms of conduction of simple MCQ quizzes. Since the course instructor has had the experience of creating quizzes on Google Classroom through Google Forms, to begin with, one of the quizzes was tried through Google Forms. The questions were prepared as a Google Form; the form was made into a quiz and was posted on
Canvas. While this strategy worked and all the students were able to take it up and the form could auto-grade the students based on the grading policy set during the creation of the form, the Google Form did not have the flexibility to set the timer which was a unique feature of built-in Canvas quizzes

To take the experimentation further, the next quiz was prepared using the popular game-based learning platform called Kahoot (Wang and Tahir, 2020). The quiz developed with this tool as shown in Fig 4, had a lot of exciting options and went well (Bicen and Kocakoyun, 2018) with the students as the students found it much more convenient to use. However, from the instructor's point of view, it still had a lacuna in terms of setting up the time limit for the quiz. Although Kahoot comes with a timer option, the timer is limited to each question and not for the whole quiz. For example, Kahoot would allow a maximum time limit to answer each of the questions which would mean that the student has to solve the question within the time limit set by the tool.

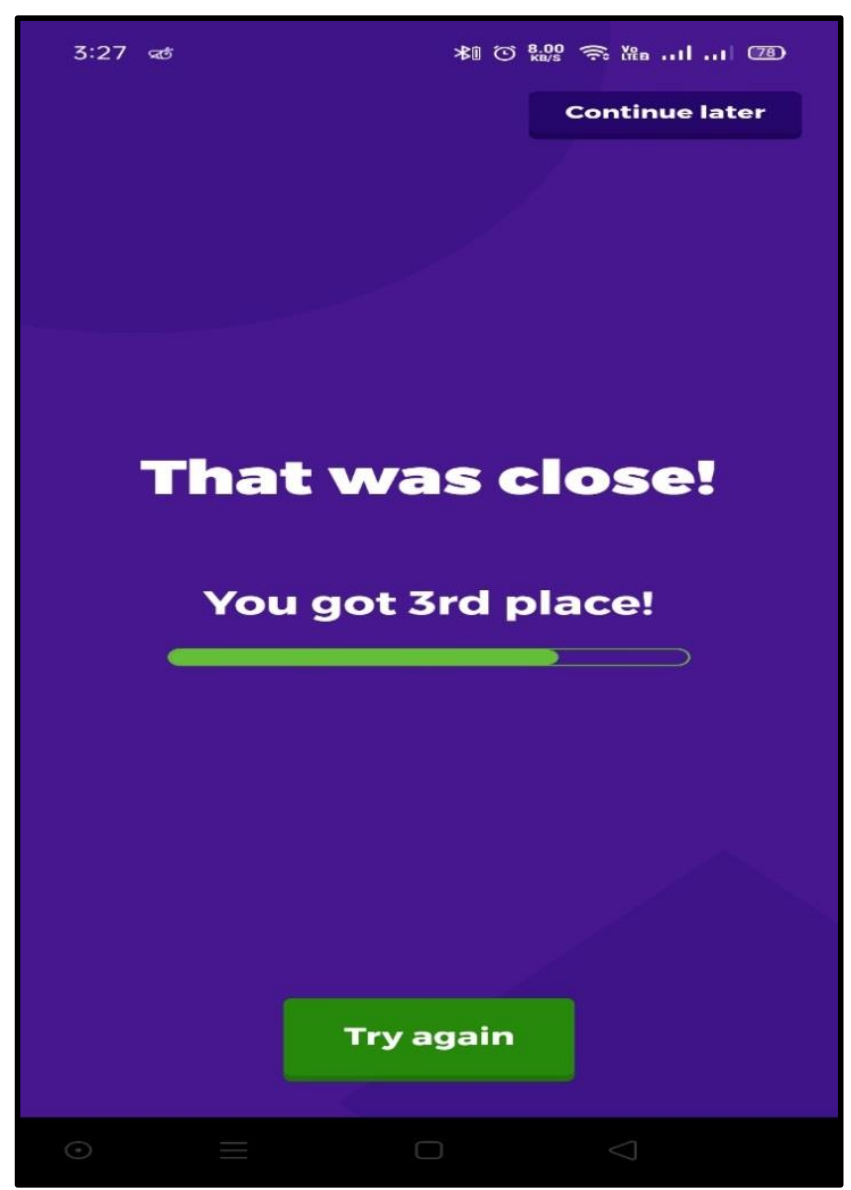

Fig. 4: Quiz developed on Kahoot

Having the freedom to set the time limit for each of the questions was a good option, but that put additional burden on students to solve the problem within the time frame set by the course instructor. This was difficult especially for logic-based questions that needed a bit more time to solve and the ability to solve these problems varied from student 
to student which makes it tricky to set a time limit for such questions. While some of the students would be able to solve it within the set time, some of the students might struggle to solve it within the stipulated time. Because of the short time limit set, they might miss out on arriving at a solution which would result in the loss of scores.

Similarly, one quiz was tried on Quizizz (Licorish et al., 2018), which again is a gamified tool to construct quick quizzes. Like in the case of Kahoot, Quizizz too had a plethora of exciting features that would attract the modernday students, but this again had problems similar to that of Kahoot. Here too, each question could be time-limited, which again would mean that the student has to solve each of the questions within the predefined time limit. However, this tool too received much appreciation from the students for its appealing user interface and ease of use.

After having used all the tools mentioned above for developing MCQs quizzes, the students were asked to rate the effectiveness of each of the tools in terms of their ease of use, accessibility and aesthetics, employing a short online survey. The results of the survey are displayed in Fig 5 .

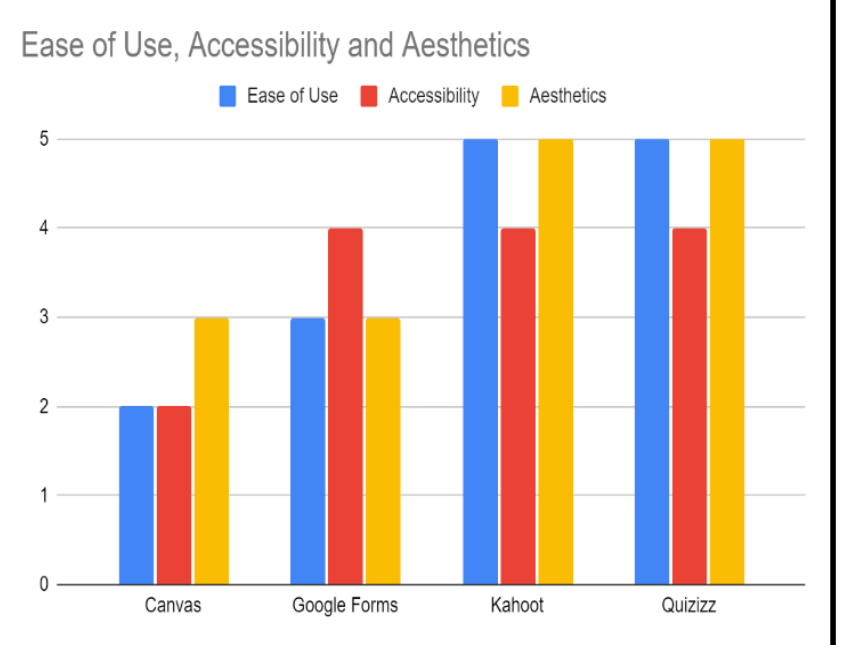

Fig. 5: Students perception of quizzes developed over multiple platforms

As indicated in Fig 5, as far as the students were concerned, Kahoot and Quizizz were right up there in terms of all parameters (Zhao, 2019). This was probably because both these tools had ample fascinating features which every millennial would desire. Also, both these tools are relatively easy to use on smartphones which is the preferred option for most of the students. Due to the mobilefriendliness, most of the students rated Kahoot and Quizizz (Göksün and Gürsoy, 2019) higher than the other two counterparts in Google Forms (Chaiyo and Nokham, 2017) and Canvas. Glaringly, the quiz prepared using the built-in quiz option on Canvas was rated the lowest by the students as it has some intrinsic issues on some of the Android phones.

On the contrary, from the point of view of the teachers, even though Kahoot and Quizizz have plenty of options, the main drawback is that they set a time limit for individual questions as opposed to the whole quiz. The absence of a timer for the entire quiz may be considered as one of the major cons of both these tools.

Since the set of participants who underwent this study had prior experience of using Google Classroom as an LMS, they were asked to rate both Google Classroom and Canvas in terms of ease of use, accessibility, mobile-friendliness and annoyance. Again, an online survey was conducted to study the findings that are shown in Fig 6 and Fig 7.

\section{Google Classroom}

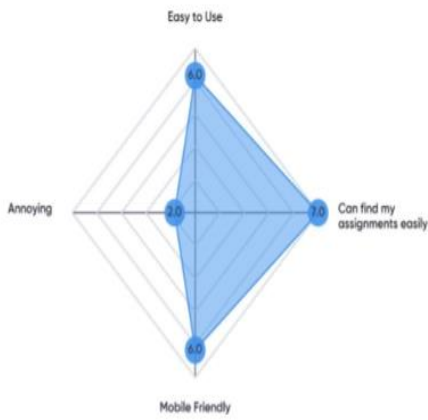

Fig. 6: Students perception of Google Classroom as an LMS

\section{Canvas}

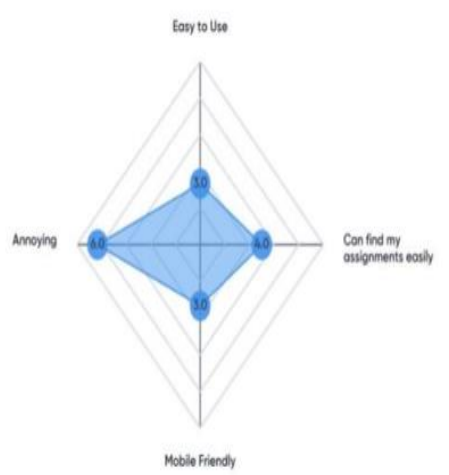

Fig. 7: Students perception of Canvas as an LMS

As the results indicate, students preferred using Google Classroom over Canvas. The main reason for this may be the fact that the students were already well versed with Google Classroom, which they had used previously, whereas Canvas was a completely new experience to them. Also, the issues with quizzes prepared on Canvas's built-in quiz option may have played a significant role in the ratings shown in Fig 6 and 7. The authors of the paper plan to assess the student preferences again towards the end of the 
semester to check the measure of the change in student perception, if any.

\section{Conclusion}

After having gone through a series of study based experimentation to gauge the impact of conducting MCQ based assessments through multiple platforms, it was observed that each of the tools had the unique features that made it different from the rest. To begin with, Canvas had the option to set the timer during a quiz. However, it ran into issues on some Android devices, and Google Forms had everything covered except the timer part, Kahoot and Quizizz were pretty intriguing but did not have the option to set the timer for the entire quiz. Also, the student's perception of all these tools led to the discovery of the fact that students prefer gamified learning environments over the traditional learning approaches. On the other hand, the comparison between Google Classroom and Canvas also revealed that the students prefer a tool that they have already made use of in the past.

In a nutshell, it can be said that no technology suits all kinds of situations. The recent advancements in technology and the current impetus on online teaching has resulted in the emergence of several novel tools that have revolutionized distance learning. With each of these tools having their pros and cons, the role of a teacher becomes much more vital as it is the teacher who has to decide the best tool that suits the requirements for any given situation. The judgement of the teacher is very critical to help to overcome the limitation of any technology.

\section{References}

Rhode, J., Richter, S., Gowen, P., Miller, T., \& Wills, C. (2017). Understanding faculty use of the learning management system. Online Learning, 21(3), 6886.

Walker, D. S., Lindner, J. R., Murphrey, T. P., \& Dooley, K. (2016). Learning management system usage. Quarterly Review of Distance Education, 17(2), 41-50.

Toquero, C. M. (2020). Challenges and Opportunities for Higher Education Amid the COVID-19 Pandemic: The Philippine Context. Pedagogical Research, 5(4).

Sinclair, J., \& Aho, A. M. (2018). Experts on super innovators: understanding staff adoption of learning management systems. Higher Education Research \& Development, 37(1), 158-172.

Adnan, M., \& Anwar, K. (2020). Online Learning amid the COVID-19 Pandemic: Students' Perspectives. Online Submission, 2(1), 45-51.

Bhat, S.. Raiu R.. Bhat S. and D'Souza R. (2020c). Redefining Oualitv in Engineering Education through the Flinned Classronm Model, Procedia Computer Science, 172, 906-914.

Priyatno, A. (2017). Promoting learner autonomy through Schoology m-learning platform in an EAP class at an Indonesian university. Teaching English with Technology, 17(2), 55-76.

Baldwin, S. J., \& Ching, Y. H. (2019). Online course design: A review of the Canvas course evaluation checklist. International Review of Research in Open and Distributed Learning, 20(3).

Kasim, N. N. M., \& Khalid, F. (2016). Choosing the Right Learning Management System (LMS) for the Higher Education Institution Context: A
Systematic Review. International Journal of Emerging Technologies in Learning, 11(6).

Bhat S., D'Souza R.. Bhat S.. Raiu R. and Kumara P. B. (2020a) Effective Denlovment of Outcome Based Education: Strategies based on Motivational Models. Iournal of Fng,ineering Education Transformation, 33, 164-169.

Kats, Y. (Ed.). (2010). Learning Management System Technologies and Software Solutions for Online Teaching: Tools and Applications: Tools and Applications. IGI Global.

Aldheleai, H. F., Bokhari, M. U., \& Alammari, A. (2017). Overview of cloud-based learning management system. International Journal of Computer Applications, 162(11).

Debuse, J. C., \& Lawley, M. (2016). Benefits and drawbacks of computer-based assessment and feedback systems: Student and educator perspectives. British Journal of Educational Technology, 47(2), 294-301.

Lee, C. A. K. O. (2016, June). Universal Design Best Practices: Recommendations for Blended and Online Learning in Higher Education with Instructure Canvas. In EdMedia+ Innovate Learning (pp. 1808-1813). Association for the Advancement of Computing in Education (AACE).

Fathema, N., \& Akanda, M. H. (2020). Effects of instructors' academic disciplines and prior experience with learning management systems: A study about the use of Canvas. Australasian Journal of Educational Technology, 113-125.

Bhat, S., Raju, R., Bikramjit, A., \& D'Souza, R. (2018). Leveraging E-learning through Google classroom: A usability study. Journal of Engineering Education Transformations, 31(3), 129-135.

Westerveld, C., \& Deenen, F. Course Design in Canvas LMS.

Wang, A. I., \& Tahir, R. (2020). The effect of using Kahoot! for learning-A literature review. Computers \& Education, 149, 103818.

Bicen, H., \& Kocakoyun, S. (2018). Perceptions of students for gamification approach: Kahoot as a case study. International Journal of Emerging Technologies in Learning (iJET), 13(02), 72-93.

Licorish, S. A., Owen, H. E., Daniel, B., \& George, J. L. (2018). Students' perception of Kahoot!'s influence on teaching and learning. Research and Practice in Technology Enhanced Learning, 13(1), 9.

Bhat S., D'Souza R.. Bhat S.. Raiu R.. and Binu K. G. (2020b) Collaborative Learning for Outcome Based Engineering Education: A Lean Thinking Annroach, Procedia Computer Science, 172, 927936.

Zhao, F. (2019). Using Quizizz to Integrate Fun Multiplayer Activity in the Accounting Classroom. International Journal of Higher Education, 8(1), 37-43.

Göksün, D. O., \& Gürsoy, G. (2019). Comparing success and engagement in gamified learning experiences via Kahoot and Quizizz. Computers \& Education, $135,15-29$

Chaiyo, Y., \& Nokham, R. (2017, March). The effect of Kahoot, Quizizz and Google Forms on the student's perception in the classrooms response system. In 2017 International Conference on Digital Arts, Media and Technology (ICDAMT) (pp. 178-182). IEEE. 